\title{
A DEMOCRATIZAÇÃO DO ACESSO À EDUCAÇÃO SUPERIOR BRASILEIRA: REALIDADE E DESAFIOS
}

\author{
LA DEMOCRATIZACIÓN DEL ACCESO A LA EDUCACIÓN SUPERIOR \\ BRASILEÑA: REALIDAD Y DESAFIOS
}

\section{THE DEMOCRATIZATION OF ACCESS TO BRAZILIAN HIGHER EDUCATION: REALITY AND CHALLENGES}

\author{
Tamiris Aparecida FACHINETTI ${ }^{1}$ \\ Eliane Aparecida Piza CANDIDO ${ }^{2}$ \\ Relma Urel Carbone CARNEIRO ${ }^{3}$
}

RESUMO: Considerando a educação como um direito humano, o presente artigo tem como objetivo discutir e analisar a Educação Superior no Brasil, que além de conservar o saber, tem o papel de formar e renovar intelectualmente a experiência humana. Dentro desta perspectiva, é possível observar que se torna preocupante a democratização do acesso diante da atual sociedade capitalista. Para fins desse estudo, realizou-se uma pesquisa bibliográfica, que apresentou como resultado um aumento significativo no número de matrículas neste nível de ensino nos últimos anos, tanto em instituições públicas quanto privadas, o que pode ser justificado pelos programas que facilitam esse acesso. Nesse contexto, espera-se estimular outras iniciativas pedagógicas, com algumas propostas que podem ser praticadas almejando a contribuição de maneira qualitativa para a expansão e a melhoria da qualidade do sistema, pois é necessário ter cautela em analisar a expansão apenas pelo viés quantitativo.

PALAVRAS-CHAVE: Educação superior. Democratização. Acesso.

RESUMEN: Considerando la educación como un derecho humano, el presente artículo tiene como objetivo discutir y analizar la Educación Superior en Brasil, que además de conservar el saber, tiene el papel de formar y renovar intelectualmente la experiencia humana. Dentro de esta perspectiva, es posible observar que se ve como preocupante la democratización del acceso delante de la sociedad capitalista actual. Para los fines de ese estudio, se realizó una investigación bibliográfica, que tuvo como resultado un aumento significativo en el número de matrículas en este nivel de enseñanza en los últimos años, tanto en instituciones públicas como privadas, lo que se justifica por los programas que facilitan ese acceso. En ese contexto, se espera estimular otras iniciativas pedagógicas, con algunas propuestas que pueden ser

\footnotetext{
${ }^{1}$ Universidade Federal de São Carlos (UFSCar), São Carlos - SP - Brasil. Doutoranda em Educação pelo Programa de Pós-Graduação em Educação. ORCID: https://orcid.org/0000-0003-4859-1471 E-mail: tamirisfachinetti@gmail.com

${ }^{2}$ Claretiano Centro Universitário (CCU), Batatais - SP - Brasil. Professor-tutor nas disciplinas de Matemática e Pedagogia dos Cursos de Graduação. Mestre em Educação pelo Programa de Pós-Graduação em Educação Escolar (UNESP). ORCID: https://orcid.org/0000-0001-6502-3834 E-mail: pizaeliane@hotmail.com

${ }^{3}$ Universidade Estadual Paulista Júlio de Mesquita Filho (UNESP), Araraquara - SP - Brasil. Docente do Departamento de Psicologia da Educação e do Programa de Pós-Graduação em Educação Escolar. Doutora em Educação Especial (UFSCar). Líder do Grupo de Estudos e Pesquisas em Educação Especial e Inclusiva (GEPEEI). ORCID: https://orcid.org/0000-0002-8961-3617 relma.urel@unesp.br
} 
practicadas anhelando la contribución de manera cualitativa para la expansión y la mejora de la calidad del sistema, pues es necesario tener precaución para analizar la expansión apenas por el punto de vista cuantitativo.

PALABRAS-CLAVE: Educación superior. Democratización. Acceso.

ABSTRACT: Considering education as a human right, this article aimed to discuss and analyze Higher Education in Brazil, which besides preserving knowledge, has the role of intellectually forming and renewing the human experience. From this perspective it is possible to observe that the democratization of the access before the present capitalist society becomes worrisome. For the purposes of this study, a bibliographical research, resulting in a significant increase in the number of enrollments at that level of education in recent years, both in public and private institutions, which may be justified by programs that facilitate such access. In this context it is hoped to stimulate other pedagogical initiatives, with some proposals that can be practiced aiming a qualitatively contribution to the expansion and improvement of the quality of the system, since it is necessary to exercise caution in analyzing the increase only by the quantitative bias.

KEYWORDS: Higher education. Democratization. Access.

\section{Introdução}

A educação é um direito humano que não deve ser negligenciado. Dessa forma, as instituições de Educação Superior têm responsabilidade social na continuidade do estudo dos alunos que queiram ingressar no nível superior de ensino, uma vez que todos os grupos sociais têm direito ao conhecimento. Ao analisarmos a Educação Superior no Brasil percebemos que ela tem se estruturado em consonância com as Políticas Públicas de Educação, assim o Estado vem transformando a organização das universidades.

Para Chauí (2003), a universidade é uma instituição indissociável do contexto social heterogêneo no qual está inserida. A universidade é um lugar em que ocorrem diferentes posicionamentos, ações, indagações, compartilhamentos, entre outros aspectos e atribuições que mostram a diversidade existente nessa instituição que é fundada na prática, na ação social e no reconhecimento público.

O art. 43 da Lei de Diretrizes e Bases da Educação Nacional (LDBEN 9.394/BRASIL, 1996) apresenta uma série de finalidades da Educação Superior. Entre elas: estimular e desenvolver o espírito científico e o pensamento reflexivo; formar os cidadãos em diferentes áreas; incentivar pesquisas; promover a divulgação de conhecimentos; prestar serviços à comunidade e estabelecer relação com a mesma, promovendo extensão aberta à população. 
A Constituição Brasileira de 1988, no seu art. 207, bem como os artigos 52, 53 e 54 da LDBEN apontam que a universidade tem como princípio indissociável o ensino, a pesquisa e a extensão (BRASIL, 1988; 1996). O espaço universitário constitui-se como um campo de produção e aplicação de conhecimento científico, assim na universidade, é possível estabelecer relações que desenvolvam a formação e capacitação do indivíduo, com uma interface entre criação, transferência e aplicação do conhecimento.

Para Sobrinho (2015, p. 585), a universidade é um ambiente de convívio plural da sociedade, em que é possível observar diferentes responsabilidades pertinentes às diversas demandas dos setores da população, a começar pela "explicitação das diferenças, por meio da crítica fundamentada em conhecimentos, valores e a prática permanente do diálogo". A universidade tem a missão de formar e contribuir para solucionar os problemas da população, de acordo com suas possibilidades e capacidades.

Nem sempre a pluralidade defendida pelo autor acima esteve presente nos ambientes universitários. Dessa forma, para compreender um pouco da Educação Superior no Brasil é importante fazer uma breve retrospectiva histórica sobre o tema, para ver como se deu a trajetória dessa modalidade de ensino, bem como verificar sua estrutura, composição e funcionamento de acordo com as políticas públicas; e finalmente interpretar as finalidades e competências que as políticas de expansão trazem para a Educação Superior e refletem na sociedade atual.

A Educação Superior no Brasil iniciou somente no século XIX, enquanto na Ilha de Hispaniola, atual República Dominicana, por exemplo, ela foi instituída ainda no século XVI. No Brasil, "as primeiras instituições de ensino superior foram criadas apenas em 1808 e as primeiras universidades são ainda mais recentes, datando da década de 1930" (DURHAM, 2005, p. 201).

No período colonial não era interessante para a Corte Portuguesa investir em instituições de ensino em terras brasileiras, porque o objetivo era a exploração econômica. Somente após a saída da Corte Portuguesa do Brasil é que se iniciou a história da Educação Superior.

As primeiras instituições universitárias foram criadas em São Paulo, no Rio de Janeiro e em Olinda. Os cursos se voltavam para as carreiras liberais e o interesse era formar profissionais para atender às necessidades do governo e da elite local. A primeira universidade, que começou a funcionar em 1930, foi a Universidade de São Paulo (USP). Com a Proclamação da República ocorreu a descentralização da Educação Superior e o surgimento de novas instituições, de caráter público e privado (DURHAM, 2005). 
A Educação Superior significou ao longo da história um espaço voltado para a formação das elites em que o acesso era para os melhores com méritos individuais. Percebe-se, assim, a presença de mecanismos de seleção e exclusão. Esse panorama começa a se modificar no período dos governos populistas (1946-1964) em que a educação passa a ter sentido "ideológico". O Estado passa a fomentar ações que ampliam o acesso como, por exemplo, a gratuidade do ensino.

Trindade (2000) faz uma retrospectiva histórica dos modelos da universidade desde que ela surgiu. Assim, do século XII até o Renascimento corresponde à invenção da universidade que inicialmente se implantou em Bolonha, na Itália, no ano 1088. Depois se ampliou para outras partes do território europeu, sempre sob a proteção da Igreja Católica. No século XV, a universidade sofreu influência do capitalismo, do humanismo, bem como da reforma e da contrarreforma. Posteriormente, com as novas descobertas científicas, aliado ao novo pensamento de valorização da razão, a tolerância religiosa e a revolução industrial inglesa, ocorreu uma transição que se estendeu até o século XIX em que as instituições universitárias começaram a oficializar a ciência. Assim, no século XIX, é instituída a universidade moderna que se tem até os dias atuais.

No Brasil, é interessante destacar a Reforma Universitária, que ocorreu no ano 1968, durante o período do regime militar (1964-1985) e atingiu as instituições de Educação Superior por meio da Lei $n^{0} 5.540 / 68$. Essa reforma apresentou mudanças significativas e produziu efeitos paradoxais, pois extinguiu a cátedra; introduziu o regime departamental; criou o sistema de créditos por disciplinas; instituiu a periodicidade semestral e aos professores o regime de dedicação exclusiva de tempo integral, bem como o ingresso e progressão referente à titulação acadêmica.

Foi no período da ditadura militar que a Educação Superior privada no Brasil ganhou força, com o incentivo à privatização do ensino e a abertura de cursos, apesar de ser questionável o bom conceito, o que comprometeu e até hoje compromete a qualidade do ensino (SILVA, 2007).

Diante do exposto, percebe-se que as mudanças que ocorrem no mundo influenciam os principais pilares de uma sociedade, entre eles a educação. Para Sobrinho (2015), a Educação Superior se transforma simultaneamente com as mudanças que se verificam na economia, na política e nas estruturas culturais. 


\section{A expansão da Educação Superior}

O processo de expansão da Educação Superior se deu por meio de estratégias e mecanismos vinculados à economia mundial que preestabelece o conhecimento como sendo um diferencial do ser humano no atual e competitivo mundo capitalista. Essas estratégias e mecanismos estão descritas nos estudos abaixo. De acordo com Mancebo et al. (2015), a expansão da educação superior no Brasil pode ser abordada por quatro eixos, sendo eles: o aumento das instituições de nível superior com fins lucrativos; algumas ações do governo federal expandindo vagas, matrículas e cursos nas instituições federais; a diferenciação de cursos, instituições e modalidades de ensino de graduação como, por exemplo, o ensino a distância $(\mathrm{EaD})$ e; a expansão da pós-graduação.

Percebemos o aumento significativo de matrículas de alunos na Educação Superior nos últimos anos. O Instituto Nacional de Estudos e Pesquisas Educacionais Anísio Teixeira (Inep) aponta que no ano 2014, 7.828.013 estudantes se matricularam em cursos superiores no país, o que representou um crescimento de 85,35\%, frente ao ano de 2004. O Censo de 2015 mostra que houve uma pequena queda no número de ingressantes na rede pública. De 2014 para 2015 o número de alunos caiu 2,6\% (BRASIL, 2015).

Para o Sindicato das Entidades Mantenedoras de Ensino Superior (SEMESP), 2016 também demonstra esse aumento de matrículas em instituições públicas e privadas no país, tendo como referência os cursos presenciais, com aumento de $141 \%$ de 2000 para 2014. É possível perceber na figura do gráfico abaixo o expressivo número de matrículas em instituições particulares, sendo em 2014 cerca de 1,8 milhões de estudantes matriculados em instituições da rede pública comparado a quase 4,7 milhões de estudantes matriculados em instituições particulares. 
Figura 1 - gráfico com matrículas de cursos presenciais no Brasil
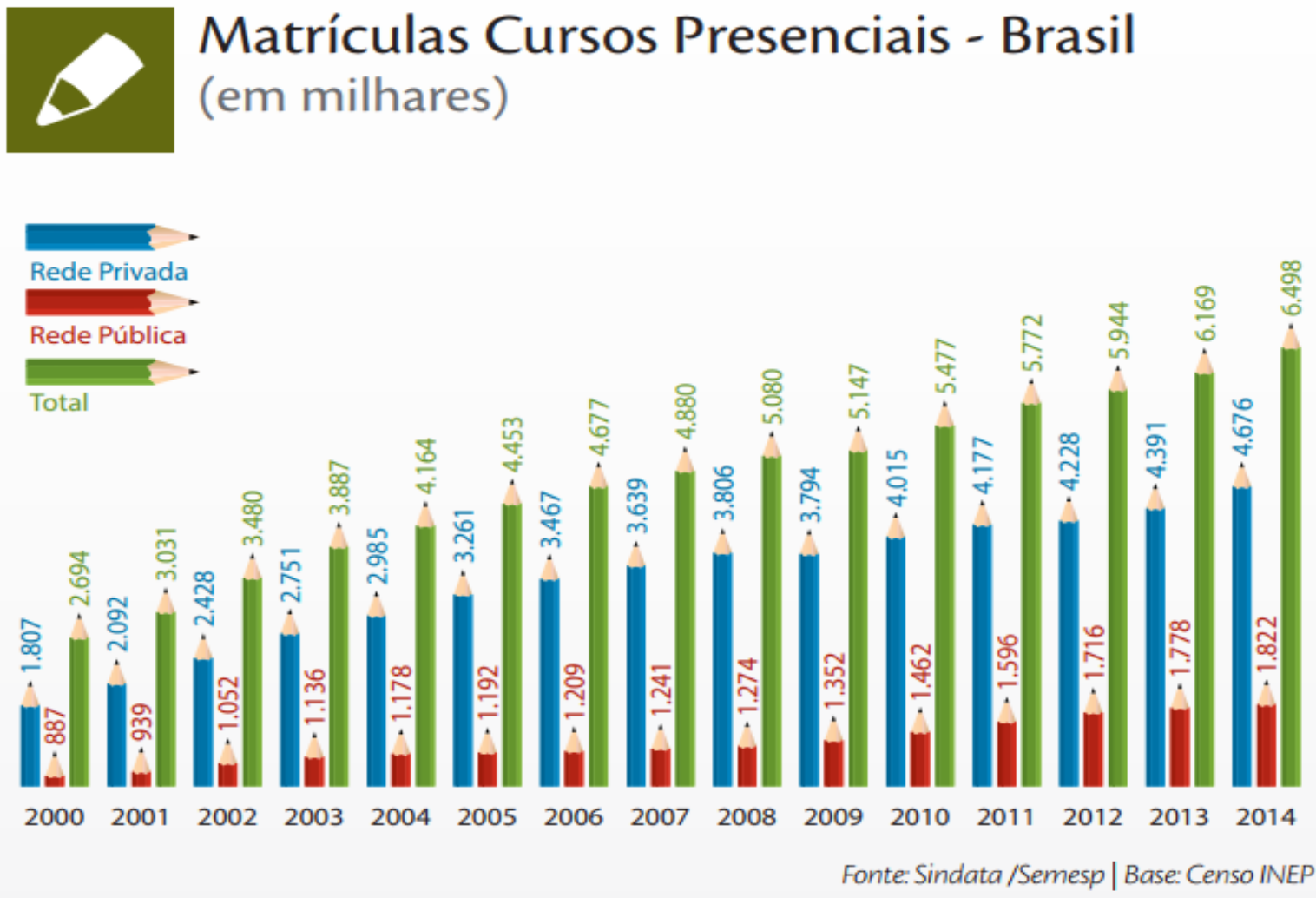

Fonte: Sindicato das Entidades Mantenedoras de Ensino Superior (SEMESP)-CENSO INEP. ${ }^{4}$

As estatísticas deixam claro que houve um aumento no número de ingressantes nos cursos de graduação. Esse aumento está associado às principais tendências de expansão já abordadas acima por Mancebo et al. (2015).

Os dados oficiais apresentados se justificam pelas maiores oportunidades que vêm sendo ofertadas aos estudantes com a implementação dos programas que facilitam o acesso à Educação Superior como: o Programa Universidade para Todos (PROUNI), que é uma iniciativa do governo federal para facilitar o acesso de alunos na Educação Superior; o Programa de Financiamento Estudantil (FIES), que é um programa do Ministério da Educação que financia cursos superiores não gratuitos e com avaliação positiva; o Exame Nacional do Ensino Médio (Enem); a intensificação dos cursos na modalidade de Educação a Distância (EaD) e; a criação de novas instituições federais e cursos que ocorreu com a implementação do Programa de Apoio a Planos de Reestruturação e Expansão das Universidades Federais (REUNI).

${ }^{4}$ Disponível em: http://convergenciacom.net/pdf/mapa_ensino_superior_2016.pdf. Acesso em: jul. 2019. 


\section{A expansão da Educação Superior privada}

O PROUNI teve sua implantação em meados de 2004. O programa tem como objetivo promover a política pública de acesso à Educação Superior para estudantes de baixa renda. Foi o principal plano no governo Lula para a democratização desta modalidade de ensino, com articulação da política fisscal, oferecendo benefícios de bolsas integrais ou parciais para garantir o ingresso de estudantes.

A condição para conseguir uma bolsa do PROUNI é ter renda familiar per capita de no máximo três salários mínimos, com pelo menos 400 pontos de média no Exame Nacional do Ensino Médio (ENEM) e ter cursado o Ensino Médio em escola pública ou em particular na condição de bolsista.

Aos estudantes bolsistas são oferecidos apenas benefícios e não direitos que garantem sua permanência. $\mathrm{O}$ fato de isentar o aluno da mensalidade dos estudos não garante que ele tenha condições de manter seus gastos com as demais despesas acadêmicas, como alimentação, xerox, materiais, além de transporte. Por mais que a universidade seja gratuita, o aluno sempre tem outros gastos para poder se manter estudando.

Na tentativa de contribuir com esses custos, a partir da Lei 11.180 de 23 de setembro de 2005, o governo passou a conceder a bolsa permanência. Apesar de ser uma iniciativa importante, é insuficiente, pois não atinge todos os estudantes necessitados. Apenas os estudantes com bolsas integrais, em cursos na modalidade presencial, com duração mínima de seis semestres, tendo como carga horária média 6 horas de aula ou mais por dia são beneficiados. Para pleitear o benefício é preciso participar do processo de seleção dos estudantes aptos a tal recebimento, que acontece mensalmente. O benefício abrange todos os meses do ano.

Além do PROUNI, o ingresso em instituições privadas também é possível através do programa de Financiamento Estudantil (FIES). O programa é destinado a financiar os estudos de instituições particulares presenciais. Podem contratar esse programa os estudantes que obtiveram média aritmética igual ou superior a 450 pontos nas provas do ENEM e nota na redação diferente de zero.

Esses programas podem ser considerados favoráveis por criarem mais possibilidades de acesso. Além disso, o fato de a expansão também ocorrer por meio de instituições privadas mostra a responsabilidade do Estado, que é assegurar o direito a educação para todos.

Almeida et al. (2012), analisam essa expansão pelo binômio "massificaçãodemocratização". De acordo com esses autores, a ampliação da Educação Superior ainda não é 
suficiente para garantir a democratização necessária que contemple uma educação de qualidade e igualdade. Para que isso se torne uma realidade é necessário que ocorram mudanças estruturais. A expansão coloca na Educação Superior a heterogeneidade de alunos e as instituições não podem uniformizar suas práticas, normas e procedimentos.

A expansão do acesso ocorreu devido à ampliação de instituições de Educação Superior privadas, o que gerou maiores oportunidades para a população brasileira. A criação de instituições privadas mostra uma nova estrutura, funcionamento e finalidade de conceber a Educação Superior, que Almeida et al. (2012) caracterizam como diversificação e diferenciação institucional.

Com base nos artigos 16 e 20 da LDBN/ 1996, Silva (2007) define a estrutura e composição da Educação Superior no Brasil em três sistemas, cada um com seu funcionamento e financiamento próprio: o federal, que é constituído pelas Instituições Federais de Ensino Superior, mantidas pela União, pelas universidades, pelos centros universitários e faculdades; o estadual, que está sob a jurisdição dos sistemas estaduais e; o municipal. As instituições privadas formam um grupo com diferença de estrutura por serem mantidas por uma ou mais pessoas físicas ou jurídicas em que se destacam os fins lucrativos.

Spatti et al. (2016), analisam as transformações da universidade pública brasileira ocorridas com a mercantilização da Educação Superior. Os autores destacam que a universidade deixou de lado seu papel enquanto instituição social por estar cada vez mais inserida na lógica de economia capitalista como prestadora de serviços. Assim, a Educação Superior passa a ter um caráter produtivista e mercantil, segundo um modelo de organização operacional (CHAUÍ, 2003).

\section{A expansão da Educação Superior pública}

O Plano Nacional de Educação (PNE) de 2001 vem consolidar o disposto no Art. 205 da Constituição Federal de 1988, na qual a educação é definida como um direito de todos e dever do Estado. Entre as metas estabelecidas pelo PNE (2001 - 2010), estava a ampliação do número de estudantes atendidos em todos os níveis da Educação Superior. Nesse contexto, inclusive para atendimento ao disposto pelo PNE e pelo Plano de Desenvolvimento da Educação (PDE), cria-se em 2007 o Programa de Apoio a Planos de Reestruturação e Expansão das Universidades Federais (REUNI), que teve como objetivo principal ampliar o acesso e a permanência de alunos na Educação Superior. 
Conforme dados informados no relatório de implementação do REUNI, publicado pelo Ministério da Educação em 30 de outubro de 2009 com o título "Reuni 2008 - Relatório de Primeiro Ano", o programa contou com um investimento em duas fases de 1,5 bilhões, o que permitiu a criação de novas vagas para ingresso, novos cursos de graduação, novas vagas para contratação de docentes e técnico administrativos, concessão de bolsas para a pós-graduação, além da ampliação de campus. O relatório demonstrou que, além do cumprimento das metas, houve ainda casos de superação das expectativas. Conforme relatório no final de 2007, todas as instituições brasileiras já haviam aderido voluntariamente ao programa.

As diretrizes para o REUNI, descritas no artigo $2^{\circ}$ do decreto $n^{\circ} 6.096 / 2007$, foram estruturadas em seis dimensões, sendo elas: Ampliação da Oferta de Educação Superior Pública; Reestruturação Acadêmico-Curricular; Renovação Pedagógica da Educação Superior; Mobilidade Intra e Inter-Institucional; Compromisso Social da Instituição e Suporte da pósgraduação ao desenvolvimento e aperfeiçoamento qualitativo dos cursos de graduação, tendo a universidade a responsabilidade de propor ações para subitens de todas as dimensões. Entre os objetivos que foram traçados para a ampliação de acesso à educação está a criação de cursos noturnos em que se objetiva atingir a demanda social.

Segundo Lamers at al. (2017), a reprovação de um curso noturno de odontologia inserido pela política de expansão na Universidade Federal do Rio Grande do Sul UFRGS, merece destaque, pois, dos 121 estudantes participantes da pesquisa, 49 encontram-se em situação de retenção, o que representa um total de $40,5 \%$ dos estudantes. Além das reprovações, ocorreram evasões que representam $19,9 \%$ no total de alunos.

Cañaveral e Sá (2017), também verificaram a evasão em cursos de graduação da Universidade Federal de Alfenas UNIFAL-MG. De acordo com os autores o compus-sede apresentava em 2013, uma taxa de abandono de 42,6\%, especificamente no curso de odontologia, para comparar com o estudo de Lamers (2017), a taxa de abandono era de 16,8\%, ou seja, 3,1\% a menos. Os cursos que apresentavam maior índice de evasão eram os cursos de licenciaturas e humanidades, dessa forma, os autores chegaram à hipótese de que a evasão está ligada com a nota de corte para ingressar na Educação Superior, quanto menor a concorrência no curso, maior a taxa de abandono. Assim verifica-se que o REUNI não intervém na ocupação de vagas.

Esses estudos justificam-se pela importância da permanência dos estudantes nos cursos de graduação, portanto, a intenção não é considerar casos específicos como uma tendência, mas utilizá-los como forma de discutir elementos para consolidar a permanência dos estudantes na Educação Superior. 
Para os autores, a criação de cursos noturnos de graduação nas instituições federais exige adaptações diversificadas e demandas particulares que as instituições podem não contemplar. Geralmente quem frequenta esses cursos realiza atividades remuneradas durante o dia. Assim, é preciso conciliar trabalho e estudo. Nesse sentido, Souza e Reinert (2010) apontam que o trabalho dos docentes é um forte requisito ao desempenho e à permanência dos alunos. Quando os professores utilizam didática e métodos adequados, mobilizam o interesse dos alunos.

Alguns autores criticam a expansão da Educação Superior proposta pelo REUNI por acreditarem que a quantidade não se associa à qualidade do ensino (CAÑAVERAL; SÁ, 2017; SOARES; SAMPAIO, 2013). A vigência do REUNI oportunizou o aumento de vagas como foi proposto. No entanto, gerou e acentuou alguns problemas como a evasão estudantil, que foi identificada e discutida por Lamers et al. (2017).

Cabe, então, ressaltar que o REUNI oferece uma possibilidade para inovação do cenário da Educação Superior, mas a quantidade deve acompanhar a qualidade, contemplando condições que favoreçam os alunos bem como o trabalho dos professores.

\section{Considerações finais}

A Educação Superior é um importante meio de produção do conhecimento científico para o avanço tecnológico em uma sociedade. Como princípio educativo e científico, a universidade é constituída pelo ensino, pesquisa e extensão.

De acordo com Trindade (2000), para buscar novos caminhos para a Educação Superior é fundamental entender os processos universitários e as políticas governamentais. Cabe ao governo definir as políticas públicas educacionais. A comunidade universitária tem como responsabilidade discutir amplamente tais políticas e avaliar suas implicações.

O conhecimento e a educação de qualidade são direitos do ser humano e não podem ser sonegados e nem negligenciados. O crescimento do número de matrículas e a democratização do acesso de estudantes menos favorecidos social e economicamente em instituições de Educação Superior nas últimas décadas ocorrem pela oferta de programas como o PROUNI, FIES e REUNI. Eles são importantes, mas ainda insuficientes para garantir a universalização do direito à Educação Superior pública e de qualidade.

Por outro lado, percebe-se atualmente uma forte tendência por parte de muitas instituições privadas de fomentar a lógica capitalista, transformando a educação em uma espécie de mercadoria. 
Outro ponto fundamental discutido neste estudo refere-se à política de expansão do REUNI. Com o objetivo de aumentar o número de matrículas em cursos de graduação em universidades federais via REUNI criou-se um contrato de gestão com o MEC, através do qual o governo se comprometeu com o aumento de recursos na ordem de $20 \%$ com despesas de custeio e pessoal. Em consequência aumentaria o número de estudantes, flexibilizaria o currículo, utilizaria a EaD e a criação de cursos de curta duração. Mas o referido programa foi alvo de críticas porque proporcionou o aumento de estudantes, mas não acompanhou o crescimento proporcional dos professores e técnicos, o que intensificou o trabalho docente.

Toda essa problemática relacionada com a ampliação da Educação Superior merece maior discussão e engajamento das comunidades universitárias para colocar em prática as políticas públicas que garantem não só o acesso, mas a qualidade educacional e a permanência de todos. Mais do que uma democratização parcial, é necessário lutar pela universalização das condições de acesso, permanência e, principalmente, pela qualidade profisssional e cidadã da Educação Superior.

É indiscutível que ocorreram mudanças com a expansão na Educação Superior e que favoreceram aspectos econômicos e sociais. Houve um processo de democratização, que é essencial nesse nível de ensino, uma vez que durante muitos anos as universidades refletiram o caráter elitista da educação. A expansão da Educação Superior também contribuiu com o desenvolvimento regional onde as novas instituições foram instaladas.

Enfim, para que ocorra uma expansão de qualidade na Educação Superior é necessário o comprometimento do Estado, do Sistema Nacional de Educação e da sociedade como um todo.

O tema é complexo. Daí a importância de ampliar a discussão e propor debates diante de um tema de relevância política e social para compreender a organização, a essência e os significados das transformações que vêm ocorrendo na Educação Superior brasileira.

\section{REFERÊNCIAS}

ALMEIDA, L. et al. Democratização do acesso e do sucesso no ensino superior: uma reflexão a partir das realidades de Portugal e do Brasil. Avaliação, Campinas; Sorocaba, v. 17, n. 3, p. 899-920, nov. 2012.

BRASIL. Assembleia Nacional Constituinte. Constituição da República Federativa do Brasil. Brasília, DF: Senado Federal/Secretaria Especial de Editoração e Publicações, 1988. Disponível em: http://www.planalto.gov.br/ccivil_03/Constituicao/Constituicao.htm. Acesso em: 09 mar. 2019. 
BRASIL. Lei n. 9.394/96, de 20 de dezembro de 1996. Estabelece as diretrizes e bases da educação nacional. Diário Oficial da União, Brasília, DF, 23 dez. 1996. Disponível em http://www.planalto.gov.br/ccivil_03/Leis/L9394.htm. Acesso em: 20 jun. 2019.

BRASIL. Ministério da Educação. Secretaria de Educação Superior. Reuni 2008 - Relatório de Primeiro Ano. Brasília, 2009. Disponível em:

http://portal.mec.gov.br/index.php?option=com_docman\&view=download\&alias=2069reuni-relatorio-pdf\&category_slug=dezembro-2009-pdf\&Itemid=30192. Acesso em: 30 jul. 2019.

BRASIL. Instituto Nacional de Estudos e Pesquisas Educacionais Anísio Teixeira. Sinopse Estatística de Educação Superior 2014. Brasília: Inep, 2015. Disponível em: http://portal.inep.gov.br/basica-censo. Acesso em: 12 jul. 2019.

CAÑAVERAL, I. C. P.; SÁ, T. A. O. REUNI: Expansão, segmentação e a determinação institucional do abandono. Estudo de caso na Unifal-MG. Rev. Cient. EccoS., São Paulo, n. 44, p. 93-115, set./dez. 2017. Disponível em:

http://www4.uninove.br/ojs/index.php/eccos/article/viewFile/7899/3650. Acesso em: 09 jan. 2019.

CHAUÍ, M. A universidade pública sob nova perspectiva. Revista Brasileira de Educação, Rio de Janeiro, v. 24, p. 5-15, set./out./nov./dez. 2003. Disponível em:

http://www.scielo.br/pdf/rbedu/n24/n24a02.pdf. Acesso em: 26 jul. 2019.

DURHAM, E. Educação superior, pública e privada (1808 - 2000). In: SCHWARTMAN, S.; BROCK, C. (Orgs.). Os desafios da educação no Brasil. Rio de Janeiro: Nova Fronteira, 2005. p. 197-240.

LAMERS, J. M. S.; SANTOS, B. S.; TOASSI, R. F. C. Retenção e evasão no ensino superior público: estudo de caso em um curso noturno de odontologia. Educação em Revista, Belo Horizonte, n. 33, e154730, p. 1-26, 2017. Disponível em:

http://www.scielo.br/pdf/edur/v33/1982-6621-edur-33-e154730.pdf. Acesso em: 30 jul. 2019.

MANCEBO, D.; DO VALE, A. A.; MARTINS, T. B. Políticas de expansão da educação superior no Brasil. Revista Brasileira de Educação, Rio de Janeiro, v. 20, n. 60, p. 31-50, jan./mar. 2015.

SILVA, H. F. O. L. Ajuste estrutural e educação superior no Brasil: princípios negados. 2007. 201 f. Tese (Doutorado em Educação) - Universidade Federal da Paraíba, Natal, 2007.

SOARES, M. L. A.; SAMPAIO, S. M. R. Reflexões acerca de ser um estudante trabalhador em uma universidade pública brasileira. Revista Congreso Universidad, La Habana, v. 2, n.2, p. 1-9, 2013.

SOBRINHO, J. D. Universidade fraturada: reflexões sobre conhecimento e responsabilidade social. Avaliação, Campinas; Sorocaba, v. 20, n. 3, p. 581-601, nov. 2015.

SOUZA, S. A.; REINERT, J. N. Avaliação de um curso de ensino superior através da satisfação/insatisfação discente. Avaliação, Campinas, v. 15, n. 1, p. 159-176, mar. 2010. 
SPATTI, A. C.; SERAFIM, M. P.; DIAS, R. B. Universidade e pertinência social: alguns apontamentos para reflexão. Avaliação, Campinas; Sorocaba, v. 21, n. 2, p. 341-360, jul. 2016.

TRINDADE, H. Saber e poder: os dilemas da universidade brasileira. Estudos Avançados, São Paulo, v. 14, n. 40, p. 122-133, 2000. Disponível em:

http://www.scielo.br/pdf/ea/v14n40/v14n40a13.pdf. Acesso em: 17 out. 2019.

\section{Como referenciar este artigo}

FACHINETTI, T. A.; CANDIDO, E. A. P.; CARNEIRO, R. U. C. A democratização do acesso à educação superior brasileira: realidade e desafios. Doxa: Rev. Bras. Psico. e Educ., Araraquara, v. 22, n. 1, p. 83-95, jan./jun., 2020. e-ISSN: 2594-8385. DOI: https://doi.org/10.30715/doxa.v22i1.13309

Submetido em: $26 / 01 / 2020$

Revisões requeridas em: 30/03/2020

Aceito em: 05/05/2020

Publicado em: 01/06/2020 